\title{
Assembling Complex Structures through Cascade and Cycloaddi- tion Processes via Non-Acceptor Gold or Rhodium Carbenes
}

\author{
Helena Armengol-Relats ${ }^{\mathrm{a}, \mathrm{b}}$ \\ Mauro Mato a,b \\ Imma Escofet ${ }^{\mathrm{a}, \mathrm{b}}$ \\ Antonio M. Echavarren*a,b (D) \\ a Institute of Chemical Research of Catalonia (ICIQ), Barcelona \\ Institute of Science and Technology, Av. Països Catalans 16, \\ 43007 Tarragona, Spain \\ aechavarren@iciq.es \\ b Departament de Química Orgànica i Analítica, Universitat Rovira \\ i Virgili, C/ Marcel.lí Domingo s/n, 43007 Tarragona, Spain
}
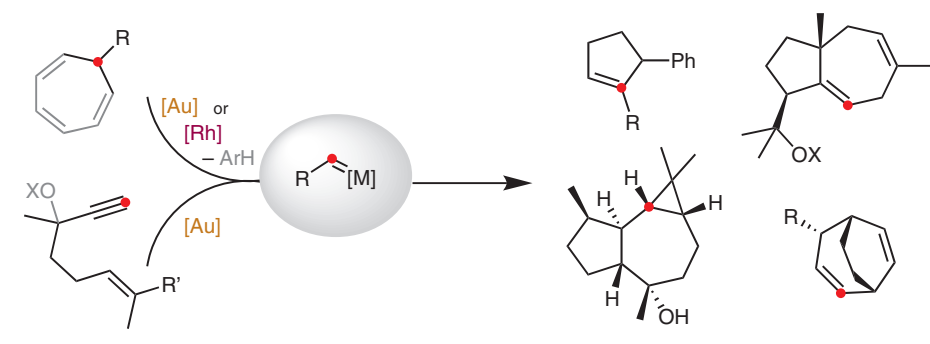

Received: 31.05 .2021

Accepted after revision: 24.06.202

Published online: 24.06 .2021

DOI: 10.1055/a-1535-3215; Art ID: ss-2021-m0319-s

License terms: cc)

(c) 2021. The Author(s). This is an open access article published by Thieme under the terms of the Creative Commons Attribution-NonDerivative-NonCommercial-License, permitting copying and reproduction so long as the original work is given appropriate credit. Contents may not be used for commercial purposes or adapted, remixed, transformed or built upon. (https://creativecommons.org/licenses/by-nc-nd/4.0/)

Abstract The ability of highly energetic metal-carbene intermediates to engage in complex cascade or formal cycloaddition processes is one of the most powerful tools for building intricate molecular architectures in a straightforward manner. Among this type of organometallic intermediates, non-acceptor metal carbenes are particularly challenging to access and, therefore, have experienced slower development. In this regard, our group has exploited the use of electrophilic gold(I) complexes to selectively activate certain classes of substrates for the generation of this type of intermediate. Thus, very different types of molecules, such as enynes or 7-substituted cycloheptatrienes, lead to the formation of carbenes under gold(I) catalysis. Related rhodium(II) carbenes can also be generated from cycloheptatrienes. In this account, we aim to summarize our efforts towards the in situ generation of such highly versatile organometallic species as well as studies on their reactivity through formal cycloadditions or complex cascade reactions.

1 Introduction

2 Generation of $\mathrm{Au}(\mathrm{I})$-Vinylcarbenes via a Cycloisomerization 1,5-Alkoxy Migration Cascade

2.1 Intramolecular Trapping of $\mathrm{Au}(\mathrm{I})$ Vinylcarbenes

2.1.1 Applications in Total Synthesis

2.2 Intermolecular Trapping of $\mathrm{Au}(\mathrm{I})$ Vinylcarbenes

2.2.1 Total Synthesis of Schisanwilsonene A

2.2.2 Trapping with Furans, 1,3-Dicarbonyl Compounds and Cyclic Alkenes

2.2.3 Mechanism of the Cycloisomerization/1,5-Migration Sequence and the Role of the OR Migrating Group

2.2.4 (4+3) Cycloadditions from Enynes

3 Formal Cycloadditions of Simple Donor Metal Carbenes

3.1 The Metal-Catalyzed Retro-Buchner Reaction

3.2 Formal Cycloadditions with Non-Acceptor Carbenes via MetalCatalyzed Aromative Decarbenations

3.2.1 (4+1) Cycloadditions of $\mathrm{Au}(\mathrm{I})$ Carbenes

3.2.2 (3+2) Cycloadditions of $\mathrm{Au}(\mathrm{I})$ Carbenes

3.2.3 (4+3) Cycloadditions of Rh(II) Carbenes

$4 \quad$ Concluding Remarks

Key words gold, rhodium, cascade reactions, cycloadditions, metal carbenes

\section{Introduction}

While the upsurge of research activity on gold chemistry focused on heterogenous catalysis, starting with the contributions of Hutchings and Haruta on the activation of acetylene and carbon monoxide, respectively, ${ }^{1}$ the group of Teles at BASF in Ludwigshafen discovered the use of triphenylphosphine gold(I) complexes as homogeneous catalysts for the activation of alkynes. ${ }^{2}$ After the development of a gold(III)-catalyzed synthesis of phenols by Hashmi, ${ }^{3}$ the groups of Fürstner, Toste and ours discovered that cationic gold(I) complexes were powerful catalysts for the electrophilic activation of $\pi$-bonds in the cycloisomerization of enynes. ${ }^{4,5}$ Thereafter, homogeneous gold catalysis experienced an almost exponential growth leading to the development of a plethora of synthetic transformations for the construction of complex carbon skeletons. ${ }^{6}$

Gold(I) complexes selectively activate alkynes in the presence of other functional groups, including alkenes. The alkynophilicity of gold $(\mathrm{I})^{4 \mathrm{a}, 7}$ is directly related to the higher reactivity of the resulting ( $\eta^{2}$-alkyne) gold(I) species towards nucleophilic attack. In general, the attack of nucleophiles takes place in an outer-sphere anti fashion, giving rise to trans-alkenyl gold complexes. ${ }^{8}$

Cycloisomerizations and cycloadditions have attracted significant attention for the assembly of complex polycyclic structures present in diverse natural products. ${ }^{9}$ These reactions typically proceed by multistep pathways that involve the formation of non-acceptor gold(I) carbene intermediates. We define non-acceptor metal carbenes as those that do not have any highly electron-withdrawing group (e.g., an ester or ketone) attached directly to the carbene carbon, but rather present electron-neutral or electron-donating functionalities. Based on this mechanistic understanding, efficient intramolecular processes that involve skeletal rearrangements, cascade processes or nucleophilic trapping have led to the discovery and development of many new gold(I)-catalyzed reactions, such as the [2+2] cycloaddition of alkynes and alkenes to afford cyclobutenes. ${ }^{10}$ 


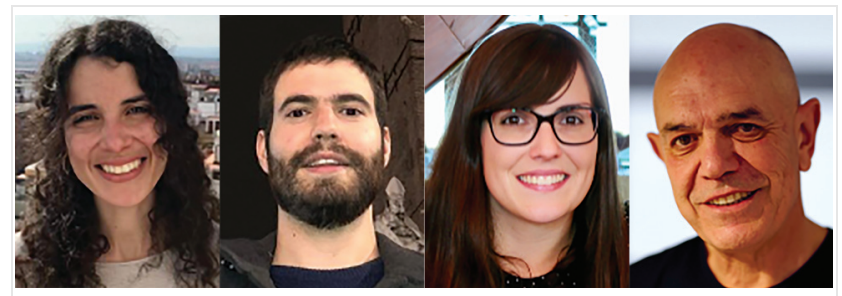

Helena Armengol-Relats studied chemistry at the University of BarceIona (UB) and completed her Bachelor's Thesis from Lund University (Sweden) under the supervision of Prof. Kenneth Wärnmark (2016). Subsequently, she obtained her Master's in synthesis, catalysis and molecular design at Rovira i Virgili University (URV) (2017) and started her Ph.D. studies under the supervision of Prof. Antonio M. Echavarren at the Institute of Chemical Research of Catalonia (ICIQ). She is currently working on the development of new gold(I)-catalyzed reactions and their applications to the total synthesis of natural products.

Mauro Mato completed his B.Sc. in chemistry at the University of A Coruña (Spain) in 2016 and his M.Sc. in synthesis and catalysis at Rovira i Virgili University (Tarragona, Spain) in 2017, receiving the Extraordinary Award for both degrees. He then started his Ph.D. studies under the supervision of Prof. Antonio M. Echavarren at the Institute of Chemical Research of Catalonia (ICIQ), where he is studying the generation and reactivity of metal carbenes. During this period, he completed a short stay at Scripps Research (San Diego, CA) under the supervision of Prof. Phil S. Baran, and received a RSEQ-Lilly Award for Ph.D. students in 2020.

Imma Escofet studied chemistry at the University of Barcelona (UB) and completed her Bachelor's Thesis in medicinal chemistry at the University of Aberdeen (Scotland, UK) under the supervision of Prof. Laurent Trembleau (2010). She subsequently moved to Tarragona to join the Prof. Antonio M. Echavarren research group at the Institute of Chemical Research of Catalonia (ICIQ) as a laboratory engineer. During this period, she also completed her Ph.D. studies (2020) working on computational mechanistic studies of gold(I) catalysis and the design of new chiral ligands.

Antonio M. Echavarren received his Ph.D. at the Universidad Autónoma de Madrid (UAM, Spain. 1982). After postdoctoral stays at Boston College (USA) and Colorado State University (USA), he joined the Institute of Organic Chemistry of the CSIC in Madrid. In 1992 he moved to the UAM as a professor, and in 2004 he was appointed as a Group Leader at the Institute of Chemical Research of Catalonia (ICIQ) in Tarragona (Spain). In 2013 he received an ERC Advanced Grant to develop gold catalysis, and in 2019 he received a second ERC Advanced Grant to develop new catalysts for the biomimetic cyclization of unsaturated substrates. He received the 2004 Janssen-Cylag Award in Organic Chemistry, the 2010 Medal of the Royal Spanish Chemical Society and an Arthur C. Cope Scholar Award from the ACS. He is currently President of the Spanish Royal Society of Chemistry (RSEQ).

In this Short Review, we provide an overview of some puzzling mechanistic pathways for the construction of complex structures through cycloadditions or cascade processes, with emphasis on the reactivity of non-acceptor gold(I) and rhodium(II) carbene intermediates developed by our group. Firstly, we describe the reactivity of vinyl gold(I) carbenes generated by the cascade isomerization of enynes. Secondly, we review the engagement of gold(I) and rhodium(II) non-acceptor carbenes, generated by retro-Buchner reactions, in formal cycloaddition processes.

\section{Generation of $\mathrm{Au}(\mathrm{I})$-Vinylcarbenes via a Cycloisomerization/1,5-Alkoxy Migration Cascade}

Gold(I) vinylcarbenes are versatile intermediate species that have been mostly generated from propargylic carboxylates ${ }^{11}$ by 1,2 -acyl migration, or from cyclopropenes ${ }^{12}$ via gold(I)-catalyzed ring opening. Our group developed an alternative approach for the generation of $\mathrm{Au}(\mathrm{I})$-vinylcarbenes by cycloisomerization/1,5-alkoxy migration of 1,6enynes 1, bearing an ether moiety on the propargylic position (Scheme 1). After activation of the alkyne by coordination to a gold(I) Lewis acid, intermediate I undergoes a 5exo-dig cyclization to form cyclopropyl gold(I)-carbene II. The propargylic ether group can then migrate to the most electrophilic position of the cyclopropane ring, giving rise to gold(I)-vinylcarbene III. These species can be intercepted intra- and intermolecularly by different nucleophiles, releasing products 2 after ligand exchange and closing of the catalytic cycle. In this section, we will discuss the different methodologies and the applications of the reactivity of this type of gold(I) vinylcarbenes after their catalytic generation by cascade cycloisomerization/1,5-alkoxy migration.

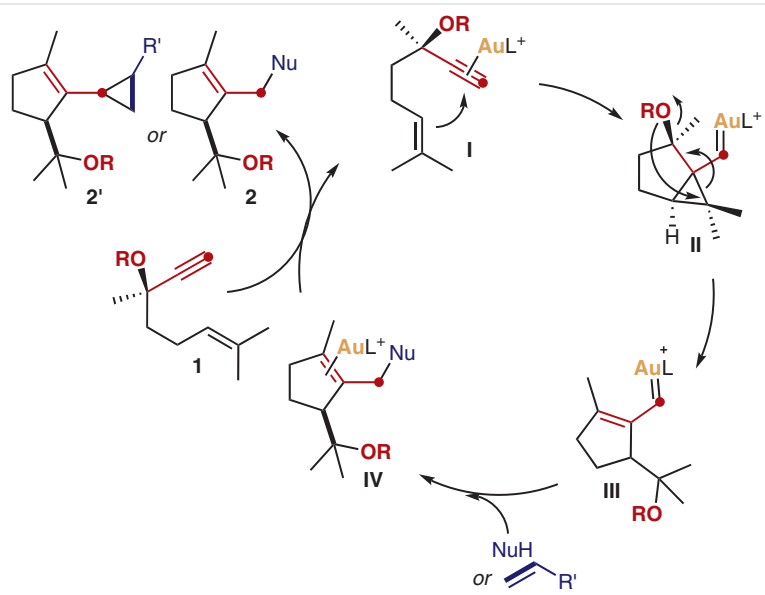

Scheme 1 General mechanism of the cycloisomerization/1,5-alkoxy migration cascade

\subsection{Intramolecular Trapping of Au(I) Vinylcarbenes}

The first example of the generation of this type of gold(I) vinylcarbene was reported by our group in 2009 via tandem cyclization/1,5-OR migration/intramolecular cyclopropanation of dienynes such as $\mathbf{3 a}$ (Scheme 2) [only the $(Z)$-isomer is depicted in the scheme]. ${ }^{13}$ The reaction proceeds through intermediate $\mathbf{V}$, which evolves through intramolecular attack of the ether moiety attached to the propargylic position on the electrophilic site of the cyclopropane to form VIa. Next, the $\alpha, \beta$-unsaturated gold-carbene 
intermediate VIIa forms upon cleavage of the oxonium bridge and undergoes an intramolecular cyclopropanation with the distal alkene on the side chain to form 4a. In the presence of an external nucleophile such as $\mathrm{CD}_{3} \mathrm{OD}$, intermediate $\mathbf{V}$ can be trapped intermolecularly prior to the aforementioned intramolecular cyclopropanation, giving rise to the corresponding deuterated epimer $\mathbf{4 b}$ in moderate yield.

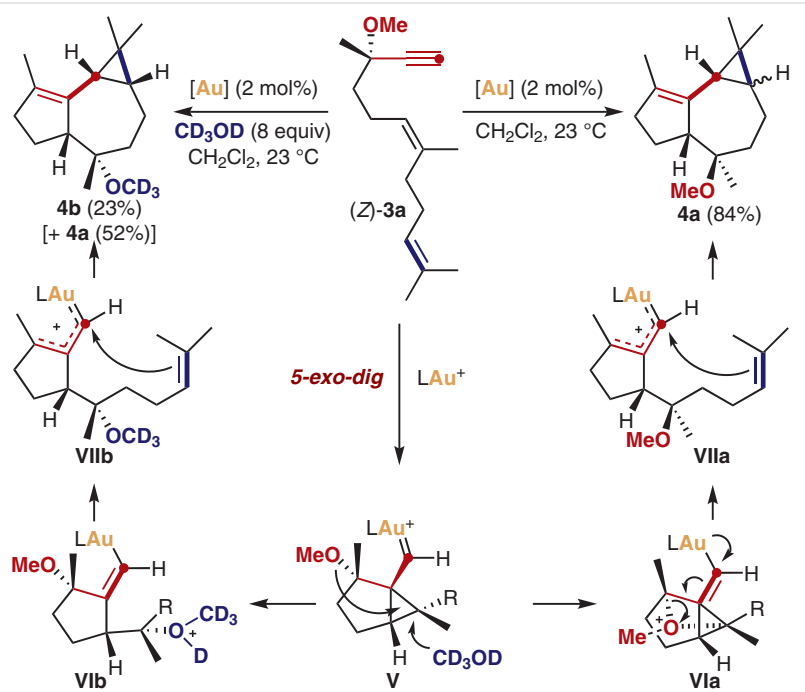

Scheme 2 Gold(I)-catalyzed tandem cyclization/1,5-OR migration/ intramolecular cyclopropanation of dienynes.

$[\mathrm{Au}]=[(\mathrm{JohnPhos}) \mathrm{Au}(\mathrm{MeCN})] \mathrm{SbF}_{6}$.

Similarly, 1,7-enynes 5 were found to undergo an analogous 1,6-shift of the methoxy group giving rise to dehydro$5 H$-benzo[c]fluorenes $\mathbf{6 a}-\mathbf{c}$ through a gold(I)-catalyzed cascade reaction (Scheme 3 ). This process proceeds via benzylic vinyl gold(I) carbene $\mathbf{X}$ followed by a Nazarov-type cyclization. Thereby, vinylogous nucleophilic addition of the aryl group to the conjugated carbene affords products $\mathbf{6 a - c}$ through intermediate XI. The methoxy migration is faster than the opening of cyclopropyl gold(I) carbene intermediate VIII, which would have delivered the corresponding tetracene derivatives by way of a formal [4+2] cycloaddition reaction. ${ }^{14}$

\subsubsection{Applications in Total Synthesis}

As shown in Scheme 2, analogous dienyne $(E)$-3b can also engage in similar processes (Scheme 4). By way of a cyclization cascade process that involves a formal 1,5-migration of an OR group, tricyclic compounds $\mathbf{4 c - d}$ were obtained, bearing the skeleton present in the sesquiterpenes globulol and epiglobulol. Hence, this method was applied in

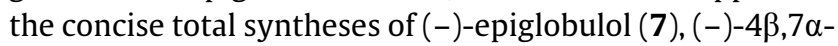
aromadendranediol (8), and $4 \alpha, 7 \alpha$-aromadendranediol (9),

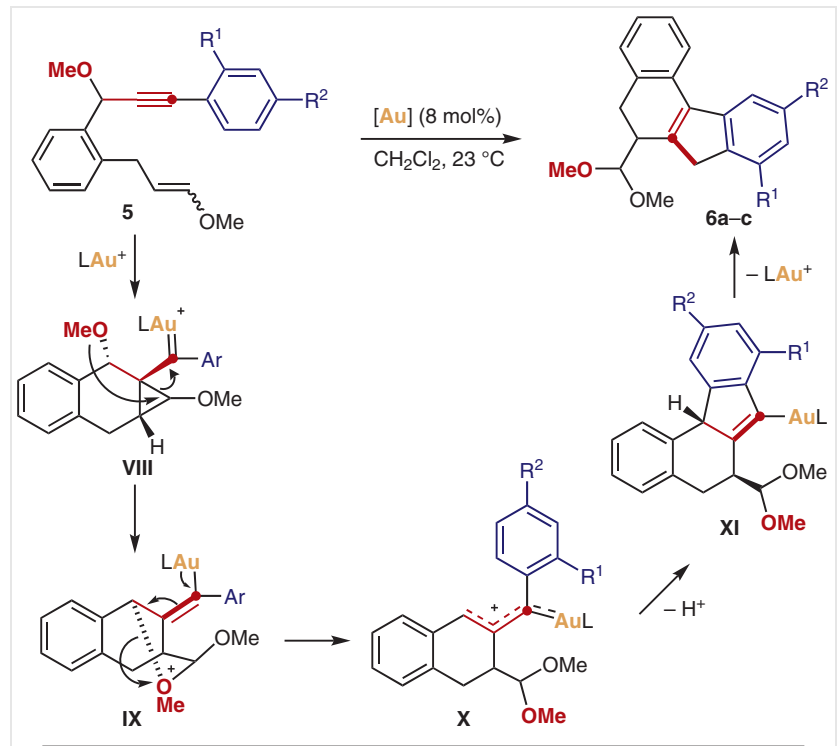

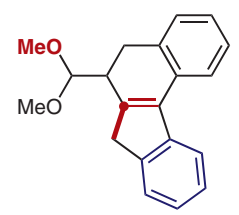

$6 a(75 \%)$

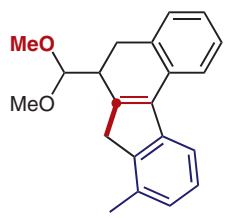

6b $(68 \%)$

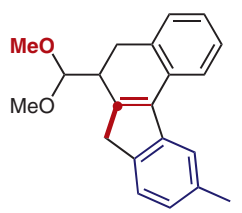

$6 c(79 \%)$
Scheme 3 A 1,6-shift of the $\mathrm{MeO}$ group in the cyclization of 1,7-enynes catalyzed by gold $(\mathrm{I}) .[\mathrm{Au}]=[(\mathrm{JohnPhos}) \mathrm{Au}(\mathrm{MeCN})] \mathrm{SbF}_{6}$.

proceeding via a stereodivergent gold(I)-catalyzed reaction which establishes four stereogenic centers in a single reaction step from (E,E)-farnesol derivative 3 (Scheme 4$) .{ }^{15} \mathrm{Re}-$ markably, polycyclizations of enynes can also involve intramolecular cyclopropanation reactions leading to complex ring systems with cis-fused cyclopropanes. The corresponding trans-fused cyclopropanes were only obtained as minor products in these cascade processes.
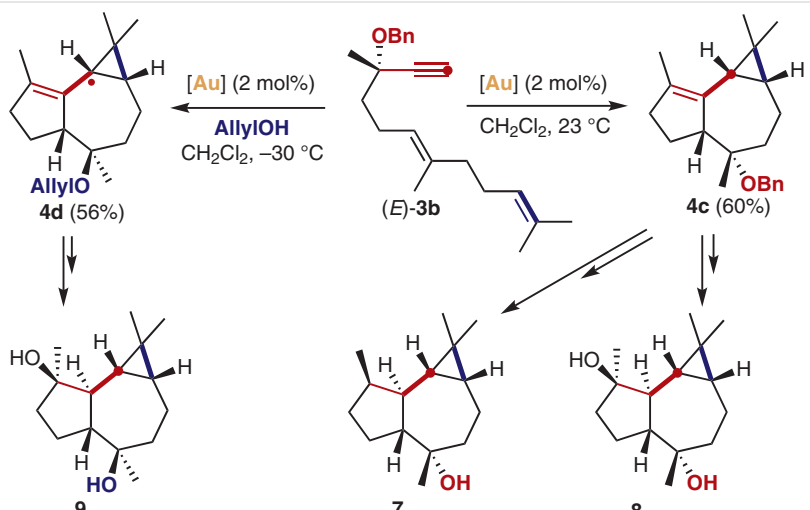

Scheme 4 Gold(I)-catalyzed total synthesis of aromadendranes. $[\mathrm{Au}]=[(\mathrm{JohnPhos}) \mathrm{Au}(\mathrm{MeCN})] \mathrm{SbF}_{6}$. 
Our group also discovered the cyclization of $1, n$-enynes 10 possessing a carbonyl group, giving oxatricyclic compounds 11 by a formal [2+2+2] alkyne/alkene/carbonyl cycloaddition cascade (Scheme 5). ${ }^{16-18}$ These reactions take place via intramolecular nucleophilic attack of the ketone in cyclopropyl gold(I) carbene XII to deliver oxonium cations XIII stereospecifically. Next, intermediate XIII undergoes a Prins-type cyclization forming tertiary carbocations XIV. Demetallation from XIV delivers products 11. Moreover, external nucleophiles such as ketones or aldehydes have been used to trap cyclopropyl gold(I) carbenes generated from 1,6 -enynes. ${ }^{19,20}$
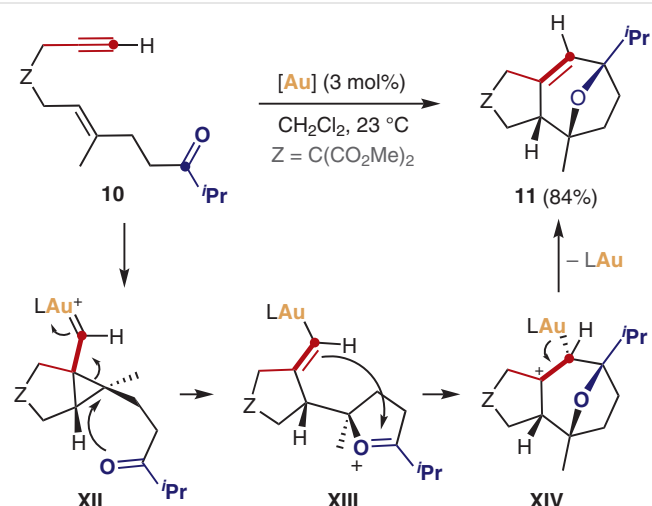

Scheme 5 Intramolecular gold(I)-catalyzed [2+2+2] alkyne/alkene/carbonyl cycloaddition of oxo-1,6-enynes. $[\mathrm{Au}]=\mathrm{AuCl}$.

This cascade cycloaddition was also applied to build the core of several oxygen-bridged sesquiterpenoids such as $(+)$-orientalol $\mathrm{F}(\mathbf{1 4})^{21}$ and the antitumor compound (-)-englerin $A(\mathbf{1 5})^{22}$ (Scheme 6). In this scenario, propargyl ether substituted enynes 12 do not undergo 1,5-migration (despite the similarity of the substrates to those in Schemes 2 and 4) due to the faster attack of the carbonyl moiety pres-

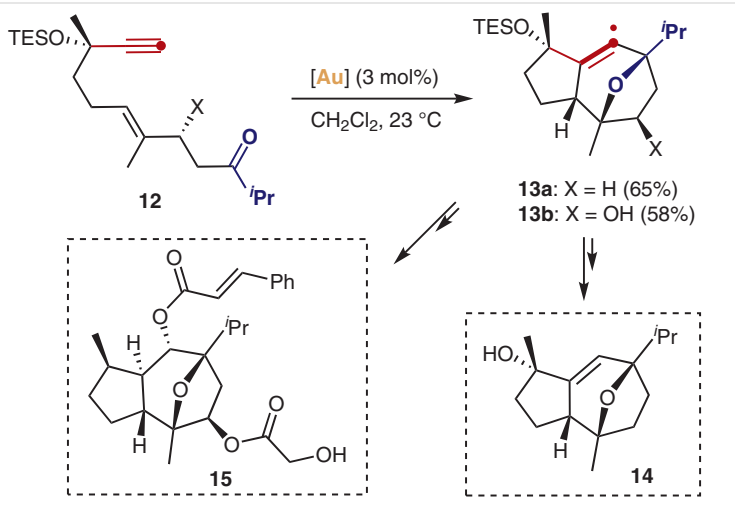

Scheme 6 Total synthesis of orientalol $F$ and (-)-englerin a catalyzed by $\operatorname{gold}(\mathrm{I}) .[\mathrm{Au}]=[(\mathrm{JohnPhos}) \mathrm{Au}(\mathrm{MeCN})] \mathrm{SbF}_{6}$. ent in the alkyl chain. Interestingly, another total synthesis of $\mathbf{1 5}$ was disclosed by $\mathrm{Ma}$ and co-workers using this gold(I)-catalyzed cascade as the key step. ${ }^{23}$

Following our retrosynthetic plan for the total synthesis of jatrophalactone (16), ${ }^{24}$ a naturally occurring diterpenoid isolated from the roots of Jatropha curcas, we developed a new gold(I)-catalyzed cyclization cascade of substituted dienynes that led to the selective formation of unexpected trans-fused cyclopropanes within a trans-bicyclo[5.1.0]octane framework, depending on the substrate geometry (Scheme 7). ${ }^{25}$ At first, in order to explore the feasibility of applying this transformation in total synthesis, the simpler model substrate 18 was designed with a phenyl ring instead of a less stable furan, expecting the formation of the cisfused cyclopropane present in jatrophalactone. However, the actual product obtained (19) had a trans-fused cyclopropane, a rather unusual stereochemical feature. This rare trans-bicyclo[5.1.0]octane motif is also present in some natural products such as cneorubin $B(\mathbf{2 0})$, emmottene (21) and hemerocallal A (22) (Scheme 7). ${ }^{26-28}$
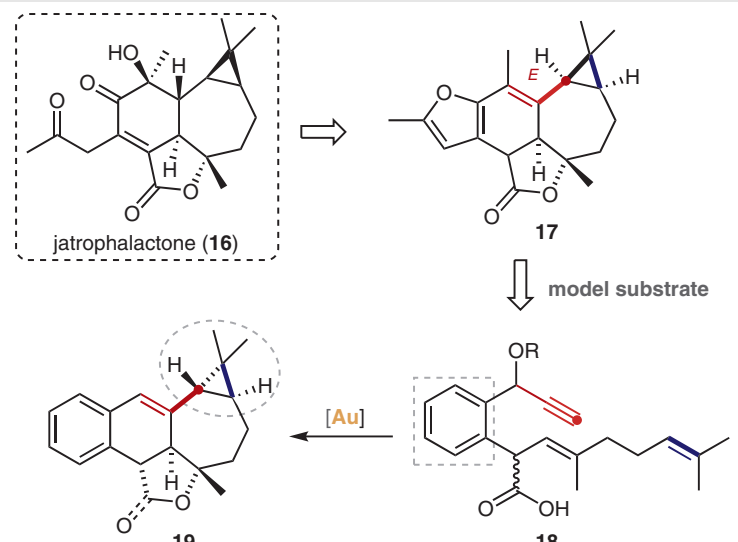

18
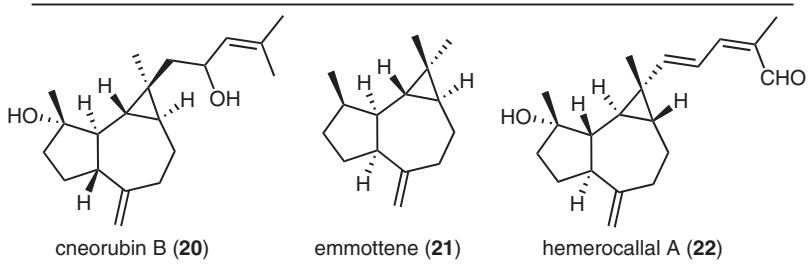

Scheme 7 Proposed retrosynthesis of jatrophalactone and examples of natural products bearing trans-fused cyclopropanes

Dienynes $(E)$ - and $(Z)-\mathbf{2 3}$ react in the presence gold(I) complexes almost instantaneously at room temperature. $(E)$-Configured enyne $(E)$-23, containing a free hydroxy group, affords trans-fused cyclopropane $\mathbf{2 4 a}$ as a single diastereomer, whereas the analogous $(Z)$-configured enyne reacts to give an inseparable mixture of isomers $24 \mathbf{b}$ and $\mathbf{2 4 c}$ in moderate yield (Scheme 8). 


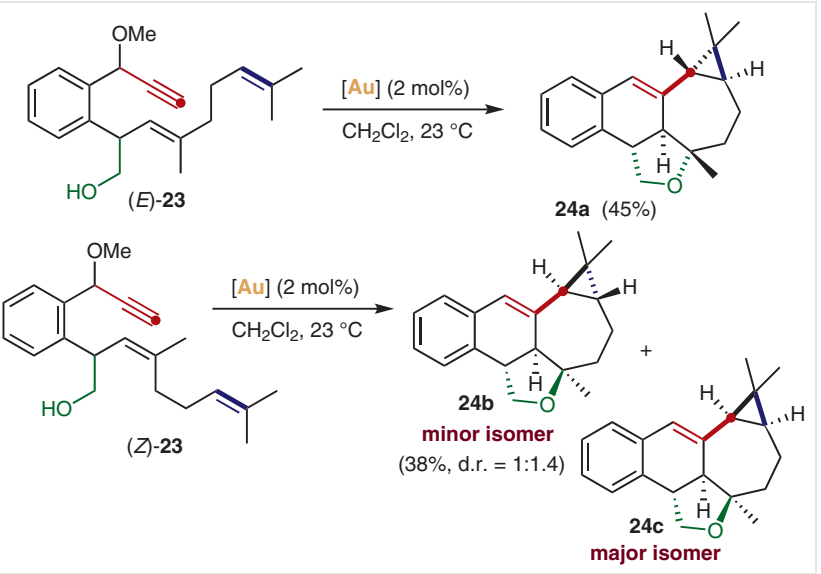

Scheme 8 Gold(I)-catalyzed cyclization cascade reactions. $[\mathrm{Au}]=[(\mathrm{JohnPhos}) \mathrm{Au}(\mathrm{MeCN})] \mathrm{SbF}_{6}$.

Intrigued by both the selective formation of trans-fused cyclopropanes and the different selectivity found with $(E)$ $/(Z)$-dienynes in these new gold(I)-catalyzed cyclization cascade reactions, we further studied these transformations by means of DFT calculations. For both substrates, direct formation of intermediates $\mathbf{X V a}$ and $\mathbf{X V \mathbf { b }}$ was postulated, via intermediates XVIa and $\mathbf{X V I b}$, by elimination of the methoxy group (Scheme 9). These computed pathways provide a rationale for the role played by the fused tetrahydrofuran ring in the final cyclopropanation step.

To better understand the selective formation of the trans-fused ring in 24a, the final cyclopropanation step was computed starting from XVa,b (Scheme 10). Under gold(I)

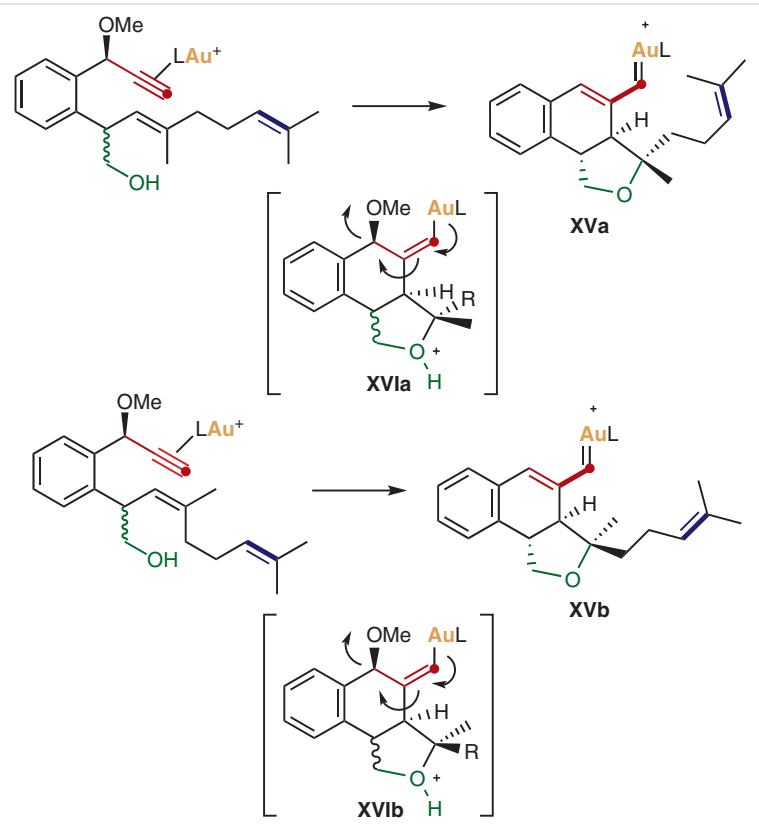

Scheme $\mathbf{9}$ Formation of intermediates $\mathbf{X V a}, \mathbf{b}$ for substrates (E)-23 and (Z)-23 catalysis, dienyne (E)-23 affords trans-fused cyclopropane 24a as a single diastereomer upon cyclopropanation of intermediate $\mathbf{X V a}$ via $\mathbf{T S}_{\mathbf{X V a}} \mathbf{x V I I a}$, which is favored by at least $7.4 \mathrm{kcal} / \mathrm{mol}$ compared to the cis-cyclopropanation pathway. The analogous diastereomeric mixture of $(Z)$-configured 23 led to a 1:1.4 mixture of cis/trans-cyclopropane products $24 \mathbf{b}$ and $\mathbf{2 4 c}$, while by calculations, competing pathways from intermediate $\mathbf{X V b}$ via $\mathbf{T S}_{\mathbf{X V b}}$-XvIIb and $\mathbf{T S}_{\mathbf{X V b} \text {-XVIIc }}$ differ by $3.4 \mathrm{kcal} / \mathrm{mol}$ (indicating that only $\mathbf{2 4 c}$ should be formed). Although the calculated energy barriers are not in agreement with the experimental results for $(Z)-23$, the ciscyclopropanation was found to be more favorable, as observed in the major isomer obtained experimentally (24c). Therefore, DFT calculations showed that the specific selectivity was directed by the rigidity of the system in the final cyclopropanation step.

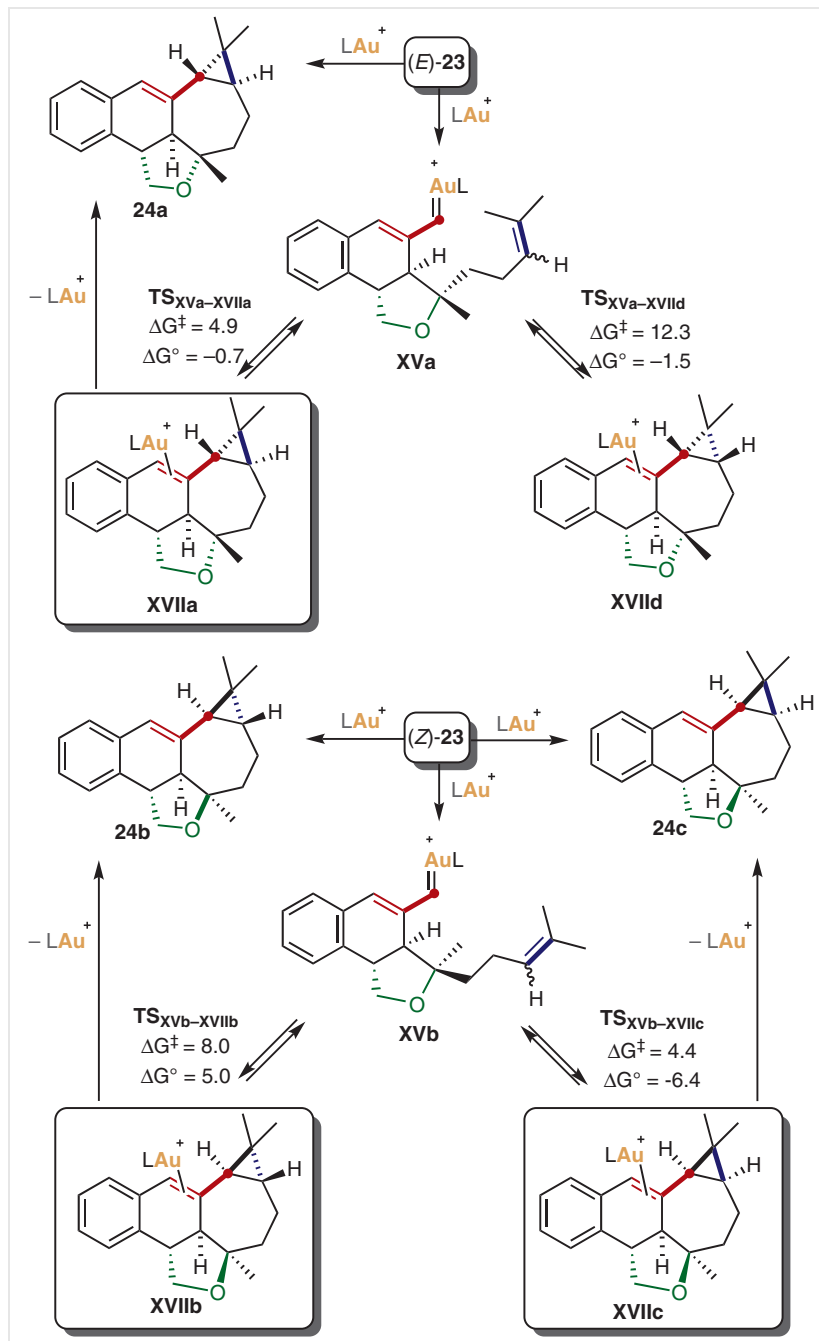

Scheme 10 DFT calculations for the formation of cis- or trans-fused cyclopropanes 


\subsection{Intermolecular Trapping of Au(I) Vinylcarbenes}

The first intermolecular trappings of this class of $\mathrm{Au}(\mathrm{I})$ vinylcarbenes were published in $2009,{ }^{13}$ in the same report as the first intramolecular version (Scheme 2). Upon 5-exodig cycloisomerization and 1,5-OR migration, the resulting gold(I) carbene was intercepted by a molecule of indole, giving product $\mathbf{2 5}$ in good yield (Scheme 11). Similarly, norbornene (26) could act as a nucleophile to deliver cyclopropane $\mathbf{2 7}$ in $75 \%$ yield and a 3.2:1 diastereomeric ratio. The use of 2,3-dimethyl-1,3-butadiene (28) as the trapping agent delivered $\mathbf{2 9}$ as the main product, together with smaller amounts of $\mathbf{3 0}$, corresponding to the $(4+3)$-cycloaddition adduct.

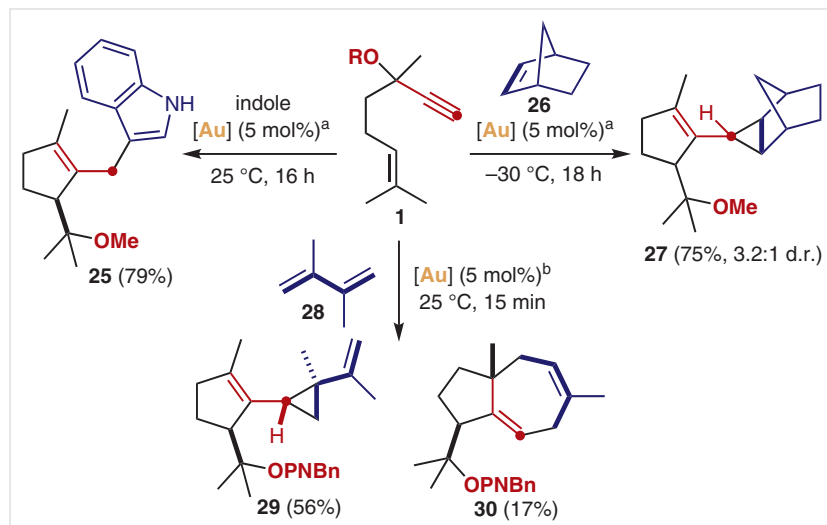

Scheme 11 First examples of gold(I)-catalyzed cycloisomerization/1,5OR migration/intermolecular nucleophilic trapping of enynes 1 . PNBn = p-nitrobenzyl. ${ }^{\mathrm{a}}[\mathrm{Au}]=[(\mathrm{JohnPhos}) \mathrm{Au}(\mathrm{MeCN})] \mathrm{SbF}_{6} ;{ }^{\mathrm{b}}[\mathrm{Au}]=$ $\left[\left(\right.\right.$ IMes) $\left.\mathrm{Au}\left((2,4,6-\mathrm{MeO}){ }_{3} \mathrm{C}_{6} \mathrm{H}_{2} \mathrm{CN}\right)\right] \mathrm{SbF}_{6}$.
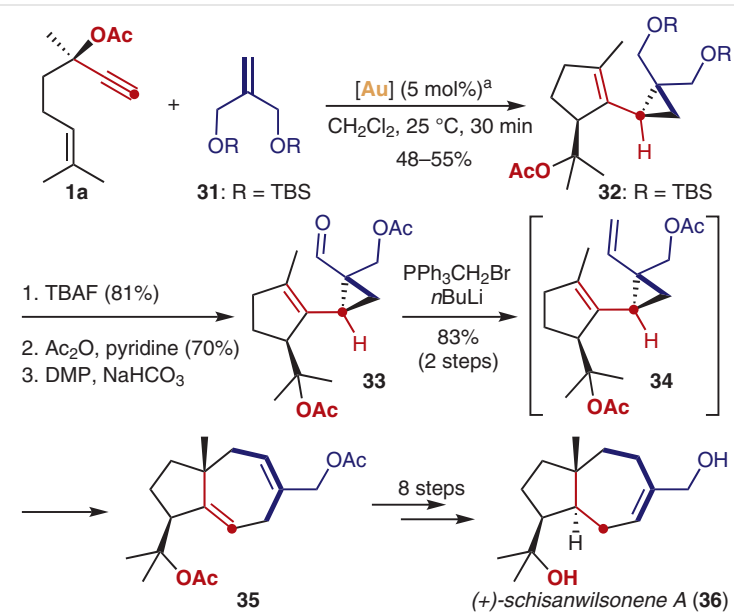

Scheme 12 Total synthesis of schisanwilsonene A. ${ }^{a}[\mathrm{Au}]=$ $[(J o h n P h o s) \mathrm{Au}(\mathrm{MeCN})] \mathrm{SbF}_{6}$.

\subsubsection{Total Synthesis of Schisanwilsonene A}

Our group demonstrated the synthetic utility of the cascade cycloisomerization/1,5-OR migration/intermolecular trapping reaction in the total synthesis of schisanwilsonene A (36). ${ }^{29}$ Thus, enyne 1a with a propargylic acetate was subjected to the gold(I)-catalyzed cycloisomerization/ 1,5-migration/intermolecular cyclopropanation cascade with alkene $\mathbf{3 1}$ to deliver cyclopropane $\mathbf{3 2}$ in moderate yield (Scheme 12). TBS deprotection, followed by monoacetylation and DMP oxidation provided aldehyde $\mathbf{3 3}$ in good yield. Aldehyde 33 was then submitted to Wittig olefination to form divinylcyclopropane 34, which underwent a [3,3]Cope rearrangement in situ, forging the fused bicyclic skeleton of 35. From this point, the first enantioselective total synthesis of schisanwilsonene A was accomplished in 8 steps. Very recently, an alternative two-stage microbial/ chemical approach to this natural product was reported by the group of Xiang. ${ }^{30}$

\subsubsection{Trapping with Furans, 1,3-Dicarbonyl Com- pounds and Cyclic Alkenes}

In 2014, our group reported the use of furans as trapping agents for gold(I) carbenes generated by different pathways. ${ }^{31}$ Gold(I) carbenes arising from the retro-Buchner reaction of cycloheptatrienes or the 1,2-acyl migration of propargylic esters reacted with furans to deliver conjugated ketones as products. Enynes $\mathbf{1}$ engage in this transformation providing products $\mathbf{3 8}$ in moderate to good yields (Scheme 13). Different substitution patterns on the furan ring were well tolerated, including methoxy-substituted furan $\mathbf{3 7 b}$, which delivered the corresponding ester $\mathbf{3 8 b}$ in moderate yield. An analogous furan with a TMSO group instead of $\mathrm{MeO}$ delivered the free carboxylic acid.

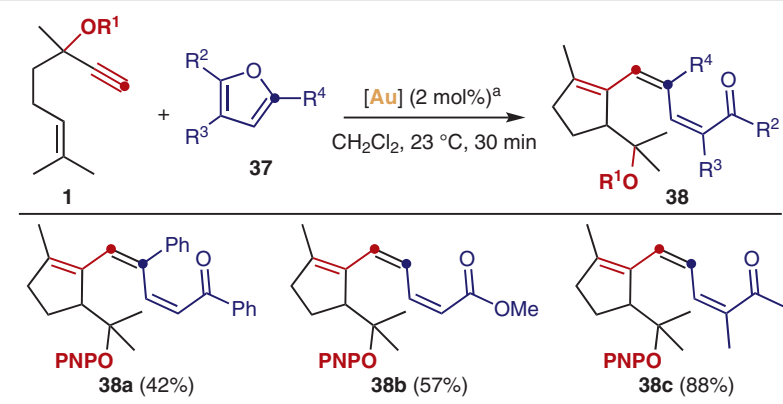

Scheme 13 Gold(I)-catalyzed cycloisomerization/1,5-OR migration/ intermolecular nucleophilic trapping of enynes 1 with furans. PNP = p-nitrophenyl. ${ }^{a}[\mathrm{Au}]=[(\mathrm{JohnPhos}) \mathrm{Au}(\mathrm{MeCN})] \mathrm{SbF}_{6}$.

The proposed mechanism for this intermolecular trapping starts with gold(I) carbene III, which reacts with furan 37 at its more nucleophilic and sterically accessible position 
(explaining the excellent regioselectivity). Finally, deauration promotes the opening of the furan ring in XVIII to deliver trienone $\mathbf{3 8}$ as a single isomer (Scheme 14).

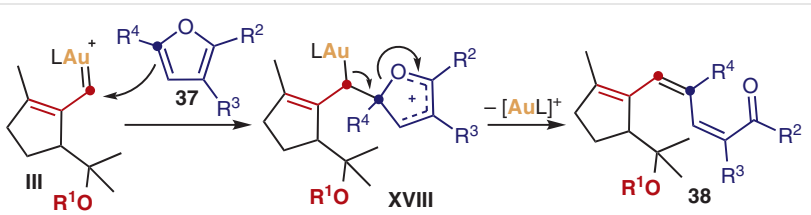

Scheme 14 Proposed mechanism for the intermolecular trapping of III with furans.

In a later report, 1,3-dicarbonyl compounds $\mathbf{3 9}$ were found to react selectively as carbon nucleophiles, delivering cyclopentenes $\mathbf{4 0}$ in moderate to good yields and with low to moderate diastereoselectivities (Scheme 15). ${ }^{32}$ The intermolecular cyclopropanation with cyclic alkenes $\mathbf{4 1}$ yielded cyclopropanes 42 (Scheme 16). Adduct 42a was obtained

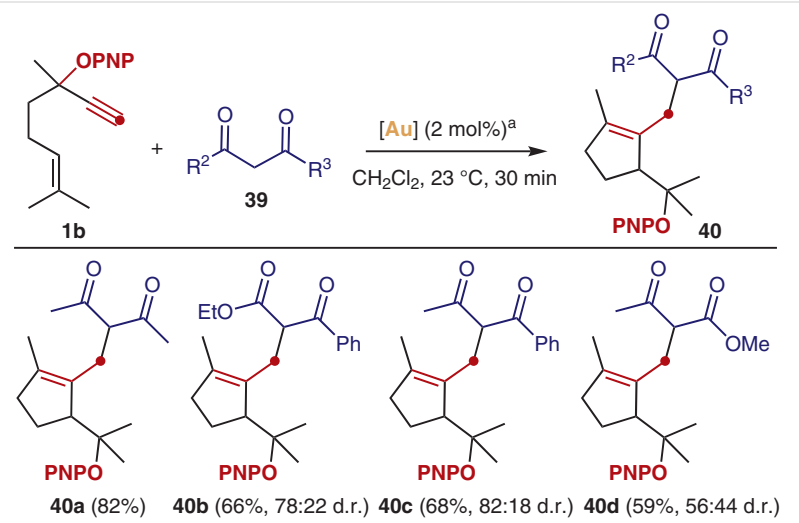

Scheme 15 Gold(I)-catalyzed cycloisomerization/1,5-OR migration/ intermolecular nucleophilic trapping of enyne $\mathbf{1} \mathbf{b}$ with 1,3-dicarbonyl compounds. $\mathrm{PNP}=p$-nitrophenyl. ${ }^{\mathrm{a}}[\mathrm{Au}]=[(\mathrm{IPr}) \mathrm{Au}(\mathrm{PhCN})] \mathrm{BAr}_{4}{ }^{\mathrm{F}}$.
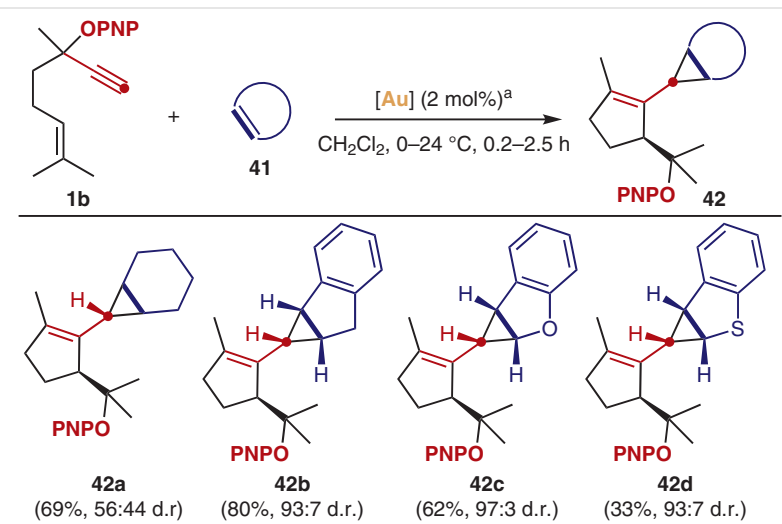

Scheme 16 Gold(I)-catalyzed cycloisomerization/1,5-OR migration/ intermolecular nucleophilic trapping of enyne $\mathbf{1} \mathbf{b}$ with cyclic alkenes. $\mathrm{PNP}=p$-nitrophenyl. ${ }^{\mathrm{a}}[\mathrm{Au}]=[(\mathrm{JohnPhos}) \mathrm{Au}(\mathrm{MeCN})] \mathrm{SbF}_{6}$. with a low 56:44 d.r., while benzene-fused alkenes delivered good to excellent diastereoselectivities (products $\mathbf{4 2 b}$ d). The relative configurations of the three newly formed stereocenters were confirmed by X-ray diffraction of crystalline 42d.

\subsubsection{Mechanism of the Cycloisomerization/1,5-Mi- gration Sequence and the Role of the OR Migrating Group}

The OR migrating group was found to have a key role in the reactivity and selectivity of this transformation. paraNitrophenyl ether was found to be optimal as the migrating group for the gold(I)-catalyzed cascade, giving the highest yields in all the previous examples. ${ }^{32}$ Additionally, in contrast to acetate-enyne 1a, the enantiomeric ratio of PNPenyne 1b was fully transferred to product $\mathbf{4 3}$ after the gold(I)-catalyzed reaction with alkene $\mathbf{3 1}$ and TBAF deprotection (Scheme 17). On the other hand, for acetoxy 1,6enyne 1a, a 10\% drop in enantiomeric excess was observed, attributed to the partial racemization by reversible 1,2-acyl migration..$^{33}$ This improvement in yield and specificity allowed for an improved synthesis of schisanwilsonene A.

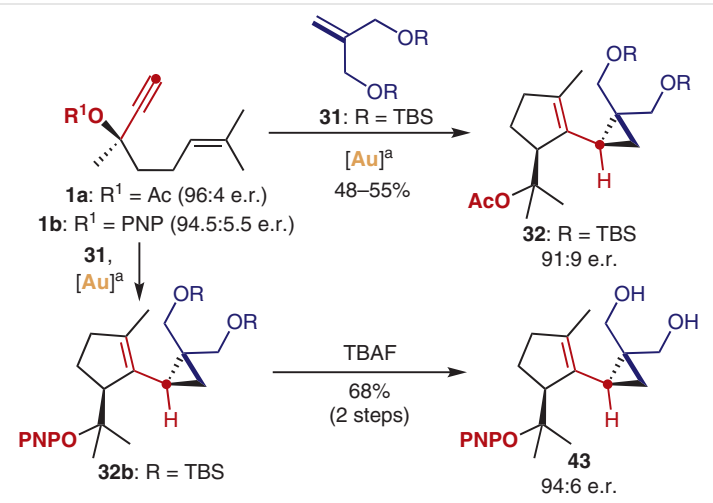

Scheme 17 Effect of the OR group on the stereospecificity. PNP = p-nitrophenyl. ${ }^{\text {a }}[\mathrm{Au}]=[(\mathrm{JohnPhos}) \mathrm{Au}(\mathrm{MeCN})] \mathrm{SbF}_{6}$.

In order to shed light on the mechanism of this cascade transformation, DFT calculations were performed for three different enynes 1, using trimethylphosphine as a simplified ligand for gold (Scheme 18). ${ }^{32}$ For all three cases, the 5exo-dig cycloisomerization of Ia-c to deliver IIa-c was favored over the 6-endo-dig pathway, which would lead to XIXa-c. The subsequent 1,5-OR migration of Ila was found to take place in a direct manner. However, for hydroxy and methoxy analogues IIb,c, the migration was found to pro-

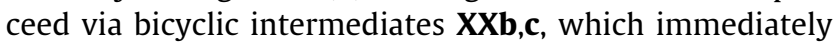
gave rise to vinyl carbenes IIIb,c with very low activation barriers. Thus, according to calculations, depending on the migrating group, the evolution of II towards III is concerted or it takes place in a two-step manner, where the second step is almost barrierless. Alternatively, intermediates IIa-c 
could evolve towards XXIa-c via single cleavage rearrangement, although the energy barriers of this pathway were found to be considerably higher.

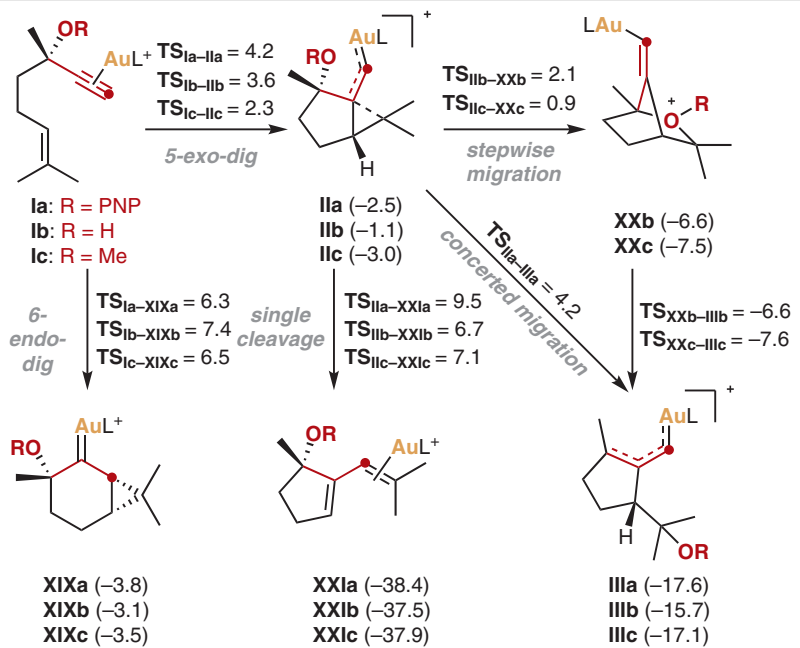

Scheme 18 DFT calculations for the cycloisomerization/1,5-migration of enynes 1. Values for free energies are in $\mathrm{kcal} / \mathrm{mol} . \mathrm{L}=\mathrm{PMe}_{3}, \mathrm{PNP}=$ p-nitrophenyl.

The calculated structure of intermediate IIIb was found to be more consistent with a gold(I)-stabilized allylic cation than with a gold(I) vinylcarbene, having very similar bond distances for $\mathrm{C} 1-\mathrm{C} 2$ and $\mathrm{C} 2-\mathrm{C} 3 .{ }^{34}$

\subsection{4 (4+3) Cycloadditions from Enynes}

The versatility of gold(I) vinylcarbenes III has been further demonstrated recently by our group, when we showed that this type of intermediate can be trapped by a 1,3-diene in a formal $(4+3)$ cycloaddition reaction. ${ }^{35}$

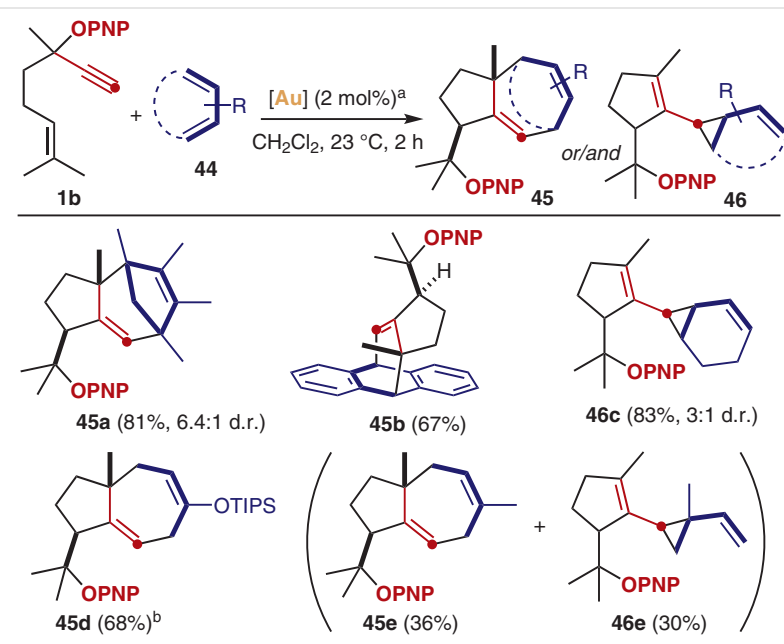

Scheme 19 Gold(I)-catalyzed cycloisomerization/1,5-OR migration/ intermolecular nucleophilic trapping of enyne $\mathbf{1} \mathbf{b}$ with 1,3 -dienes. $\mathrm{PNP}=p$-nitrophenyl. ${ }^{\mathrm{a}}[\mathrm{Au}]=[(\mathrm{JohnPhos}) \mathrm{Au}(\mathrm{MeCN})] \mathrm{SbF}_{6}$.
We found that the reaction of enyne $\mathbf{1 b}$ with $1,2,3,4-$ tetramethylcyclopentadiene delivered $\mathbf{4 5 a}$ in good yield and moderate diastereoselectivity under gold(I) catalysis. Anthracene was also found to be a good reaction partner for this $(4+3)$ cycloaddition, delivering $\mathbf{4 5 b}$ in $67 \%$ yield. Contrarily, 1,3-cyclohexadiene delivered simple cyclopropanation product $46 \mathbf{c}$ in good yield and moderate diastereoselectivity, with only traces of the corresponding $(4+3)$ adduct. An acyclic 2-oxy-1,3-diene was found to deliver the desired bicyclic core in good yield (45d), whereas isoprene delivered a 1.2:1 mixture of (4+3) product 45e versus cyclopropane 46e (Scheme 19).

Experimental mechanistic investigations revealed that a Cope rearrangement of products $\mathbf{4 6}$ to give products $\mathbf{4 5}$ was not taking place under the reaction conditions, neither thermally nor catalyzed by gold(I). DFT calculations of the full system provided reasoning for the different product selectivity depending on the diene. For instance, experimentally, the reaction of $\mathbf{1 b}$ with cyclopentadiene delivered a $2: 1$ ratio of cyclopropane/(4+3) adduct, in perfect agreement with the theoretically predicted ratio. In this model, intermediate IIId is trapped by cyclopentadiene, forming carbocation XXII. This intermediate can then undergo ring closing towards the three- or the seven-membered rings via $\mathbf{T S}_{\mathbf{X X I I}}$ XXIV and $\mathbf{T S}_{\mathbf{X X I}}$-XXIII, respectively. Under kinetic control, the energy difference between these two transition states determines the ratio of the final products (Scheme 20).

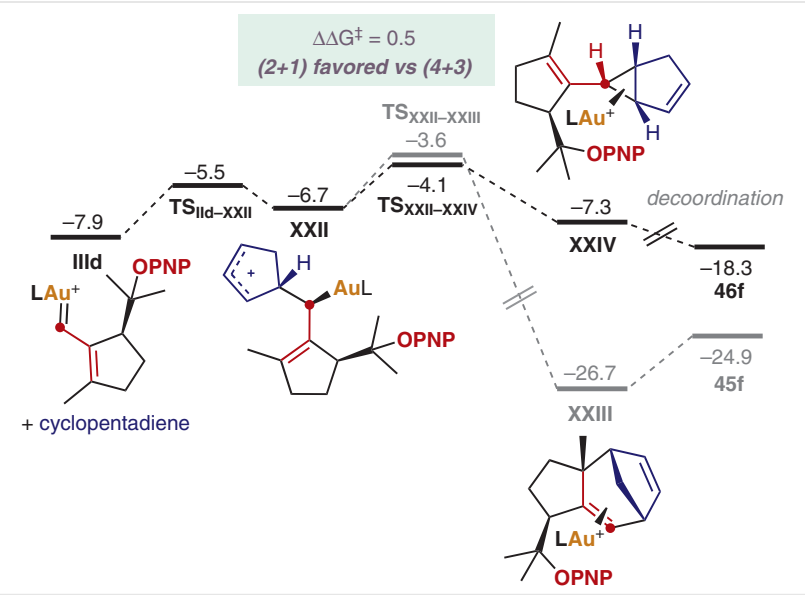

Scheme 20 DFT calculations for the intermolecular trapping of IIId with cyclopentadiene. $L=$ JohnPhos; PNP = p-nitrophenyl.

\section{Formal Cycloadditions of Simple Donor Metal Carbenes}

Besides enynes, other precursors have been studied to generate simpler donor metal carbenes. As already discussed, metal carbenes have been found to engage in formal cycloadditions, which can be defined as processes that re- 
semble traditional cycloadditions but are not concerted pericyclic reactions. Instead, a series of charged intermediates are involved in a sequence that takes place through two or more mechanistic steps. Although these processes have been widely studied with acceptor carbenes, ${ }^{36}$ there are fewer reports describing formal cycloadditions of simple non-acceptor metal carbenes. ${ }^{37}$ This is mostly due to the prevalence of methods that lead to the generation of acceptor or donor-acceptor metal carbenes. ${ }^{38}$ The decomposition of stabilized diazo compounds is the most illustrative example, ${ }^{39}$ since non-acceptor diazo compounds are often toxic, difficult to prepare, handle or store, and can be explosive in pure form. ${ }^{40}$ Together with enynes (described in the first part of this account), propargyl esters, ${ }^{33}$ and cyclopropenes, ${ }^{41}$ 7-substituted cycloheptatrienes have recently emerged as versatile and safe alternatives to generate nonacceptor metal carbenes through an aromative decarbenation by retro-Buchner reaction. ${ }^{42}$ These gold(I) and rhodium(II) carbenes generated in situ can engage in a variety of formal cycloadditions.

\subsection{The Metal-Catalyzed Retro-Buchner Reaction}

In 2010, while exploring the gold(I)-catalyzed cycloisomerization of 1,6-enynes, our group discovered the possibility of generating aryl carbenes through a process driven by the downhill release of an aromatic fragment. ${ }^{42,43}$ This concept led us to the discovery of the gold(I)-catalyzed retro-Buchner reaction of 7-substituted cycloheptatrienes 47, an aromative decarbenation process in which a carbene fragment $\mathbf{X X V}$ is generated upon release of a molecule of benzene. This resulted in the development of a safe and practical method for the arylcyclopropanation of alkenes (Scheme 21). ${ }^{44}$ The same concept could then be extended to develop a diastereoselective alkenylcyclopropanation of alkenes. ${ }^{45}$ The generation and fate of these non-acceptor carbenes was studied in detail, and it was also found to be possible to trap these intermediates intramolecularly through Friedel-Crafts-type mechanisms. ${ }^{46}$

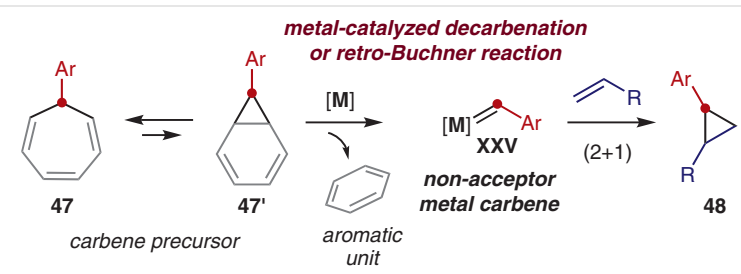

Scheme 21 Metal-catalyzed aromative decarbenation by retro-Buchner reaction of cycloheptatrienes to give non-acceptor carbenes.

Through the design and development of a new generation of more reactive cycloheptatrienes, these carbenetransfer processes could not only be carried out under much milder conditions, but also under zinc(II) ${ }^{47}$ or rhodi-
um(II) catalysis. ${ }^{48}$ These discoveries allowed the development of new methodologies that were previously inaccessible under gold(I) catalysis, such as $\mathrm{Si}-\mathrm{H}$ insertion reactions ${ }^{48}$ or a sequence involving the one-pot assembly and disassembly of non-acceptor cyclopropyl ethers to give allE trienes. ${ }^{49}$

\subsection{Formal Cycloadditions with Non-Acceptor Car- benes via Metal-Catalyzed Aromative Decarbena- tions}

Among the different types of reactivities in which nonacceptor metal carbenes generated by retro-Buchner reactions can engage, formal cycloadditions stand out for their potential to rapidly build up molecular complexity.

\subsection{1 (4+1) Cycloadditions of Au(I) Carbenes}

In 2014, we found that the reaction of 7-aryl-1,3,5-cycloheptatrienes $\mathbf{4 7}$ with methylenecyclopropanes $\mathbf{4 9}$ under gold(I) catalysis led to cyclopentenes $\mathbf{5 0}$ (Scheme 22). ${ }^{50}$ These would be the products of formal $(4+1)$ cycloaddition between the four carbon atoms of the methylenecyclopropane and the corresponding aryl gold(I) carbene generated by aromative decarbenation of cycloheptatrienes 47 . In this manner, a range of 1,5-disubstituted cyclopentenes $\mathbf{5 0}$ could be assembled in moderate to excellent yields.

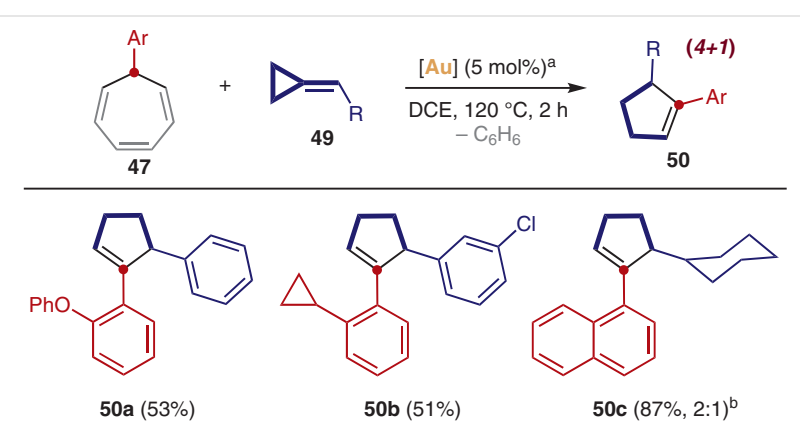

Scheme $22(4+1)$ Cycloaddition between aryl gold(I) carbenes and methylenecyclopropanes. ${ }^{\text {a }}[\mathrm{Au}]=[(\mathrm{JohnPhos}) \mathrm{Au}(\mathrm{MeCN})] \mathrm{SbF}_{6} .{ }^{\mathrm{b}}$ The minor isomer corresponds to 3-cyclohexyl-3-naphthylcyclopent-1-ene.

Based on experimental observations, a mechanistic proposal involving three different gold(I)-catalyzed processes was drawn up. The first step is the gold(I)-catalyzed ringexpansion isomerization of methylenecyclopropanes to afford cyclobutenes 51 (Scheme 23, left cycle). Next, the retro-Buchner reaction of 7-arylcycloheptatrienes $\mathbf{4 7}$ would give rise to aryl gold(I) carbenes $\mathbf{X X V}$, which would cyclopropanate the cyclobutene to afford bicyclic intermediates XXIX (as evidenced by its isolation in some particular cases). Finally, a ring opening followed by a $1,2-\mathrm{H}$ shift affords cyclopentenes $\mathbf{5 0}$, in a process also catalyzed by gold (Scheme 23, right cycle). 


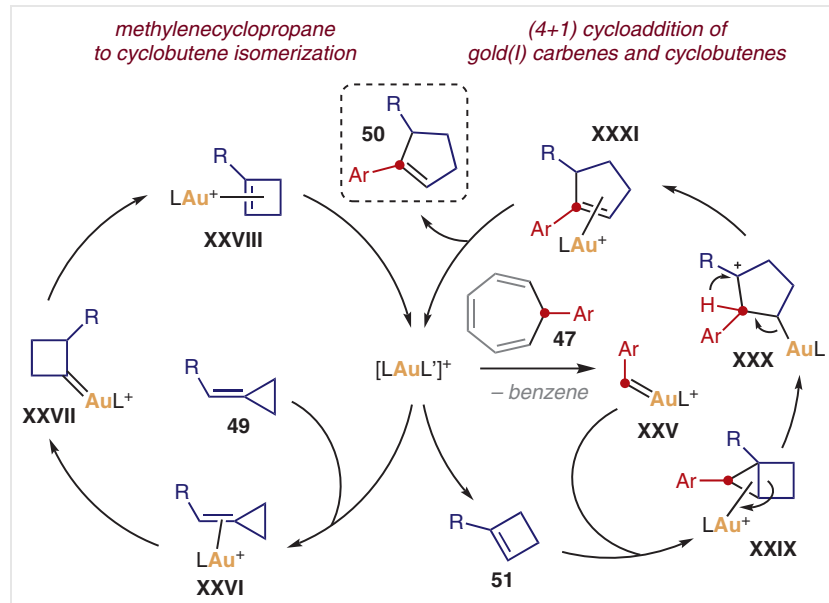

Scheme $23(4+1)$ Cycloaddition via triple gold(I) catalysis

The fact that cyclobutenes $\mathbf{5 1}$ are indeed intermediates in this transformation could be exploited to develop an analogous methodology in which these substrates are used directly instead of methylenecyclopropanes. This allowed access to other cyclopentenes $\mathbf{5 0}$ with a broader range of substitution patterns (Scheme 24).

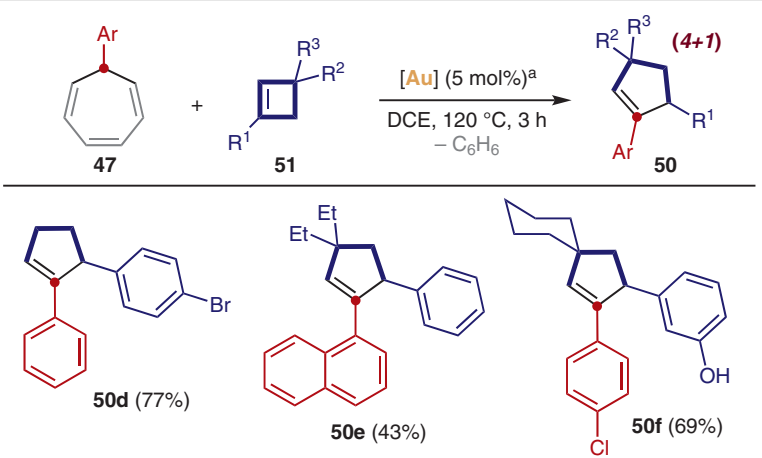

Scheme $24(4+1)$ Cycloaddition between aryl gold(I) carbenes and cyclobutenes. ${ }^{\mathrm{a}}[\mathrm{Au}]=[(\mathrm{JohnPhos}) \mathrm{Au}(\mathrm{MeCN})] \mathrm{SbF}_{6}$.

This tandem gold(I)-catalyzed chemistry could be taken one step further by generating the corresponding cyclobutene in situ by [2+2] cycloaddition of an alkene and an arylacetylene, a process which is also promoted by the same catalytic system. ${ }^{51}$

\subsection{2 (3+2) Cycloadditions of $\mathrm{Au}(\mathrm{I})$ Carbenes}

In 2017, we reported that the same type of aryl gold(I) carbenes react with allenes to give indenes through a formal (3+2) cycloaddition reaction..$^{52}$ In this manner, we synthesized a variety of highly substituted indenes by reactions of 7-arylcycloheptatrienes $\mathbf{4 7}$ and 1,2-disubstituted allenes 52 by using a cationic gold(I) complex as the catalyst
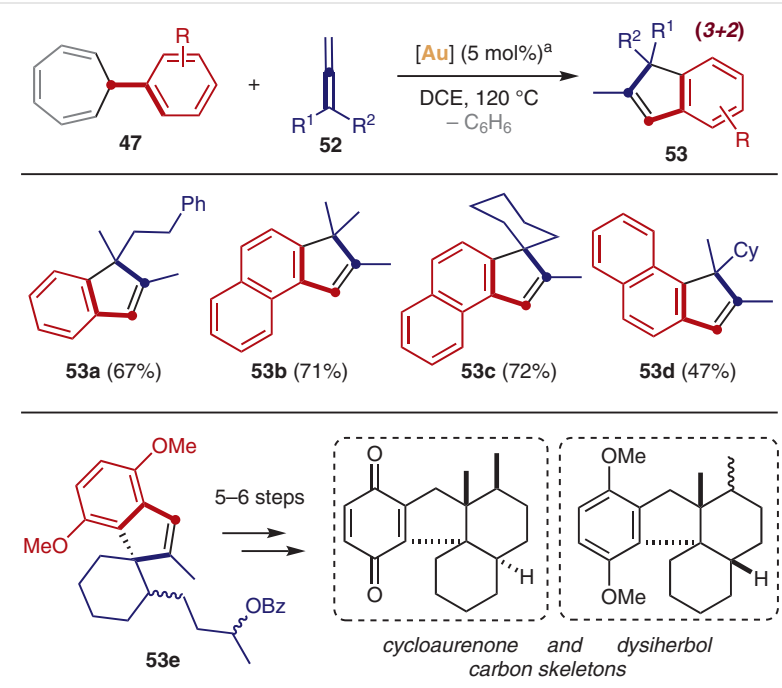

Scheme $25(3+2)$ Cycloaddition of aryl gold(I) carbenes and allenes. Assembly of the carbon skeletons of two families of natural products. ${ }^{a}[\mathrm{Au}]=[($ JohnPhos $) \mathrm{Au}(\mathrm{MeCN})] \mathrm{SbF}_{6}$.

(Scheme 25, top). This strategy allowed the preparation of indene intermediate 53e, which after elaboration through 5-6 more steps led to the construction of the carbon skeletons of both the cycloaurenones and the dysiherbols, ${ }^{53}$ two families of natural products featuring a cis- or trans-decalin core, respectively (Scheme 25, bottom).

In addition, we found that if 7-styrylcycloheptatrienes $\mathbf{5 4}$ were used as carbene precursors, the same allenes reacted to give cyclopentadienes 55 (Scheme 26). ${ }^{52}$ Thus, we prepared different arylcyclopentadiene derivatives with dense substitution patterns, which are significantly challenging to construct by other means. We illustrated the power of this transformation by performing the shortest total synthesis of laurokamurene B (56) reported thus far. A simple and selective hydrogenation of cyclopentadiene 55d using Wilkinson's catalyst afforded the natural product in $39 \%$ overall yield over three total steps.

The mechanistic proposal for this transformation is depicted in Scheme 27. First, styryl gold(I) carbene XXXII is generated by aromative decarbenation of 54a. This is followed by a nucleophilic attack by the central carbon of the allene on the highly electrophilic carbene carbon, affording cationic intermediate $\mathbf{X X X I I I}$ which evolves via a vinylogous Friedel-Crafts-type cyclization to afford exocyclicalkene intermediate $\mathbf{5 7}$. Both diastereoisomers of this product could be observed and characterized by NMR. The final step of the reaction involves a downhill isomerization to afford fully conjugated cyclopentadiene $\mathbf{5 5 e}$.

The very same mechanistic picture can be extended to the $(3+2)$ cycloaddition between allenes and aryl carbenes (Scheme 25), considering a classical Friedel-Crafts-type cyclization instead of a vinylogous one. 

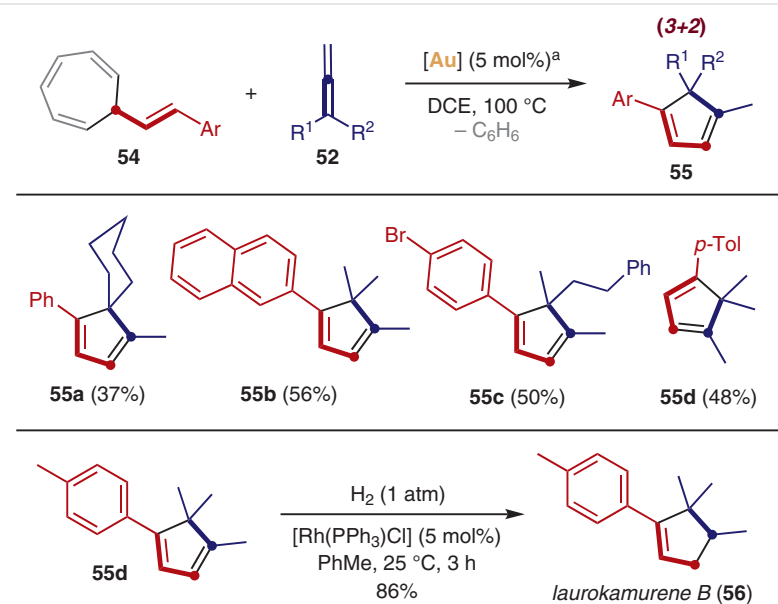

Scheme $26(3+2)$ Cycloaddition of styryl gold(I) carbenes and allenes. Total synthesis of laurokamurene B. ${ }^{\mathrm{a}}[\mathrm{Au}]=[(\mathrm{tBuXPhos}) \mathrm{Au}(\mathrm{MeCN})] \mathrm{SbF}_{6}$.

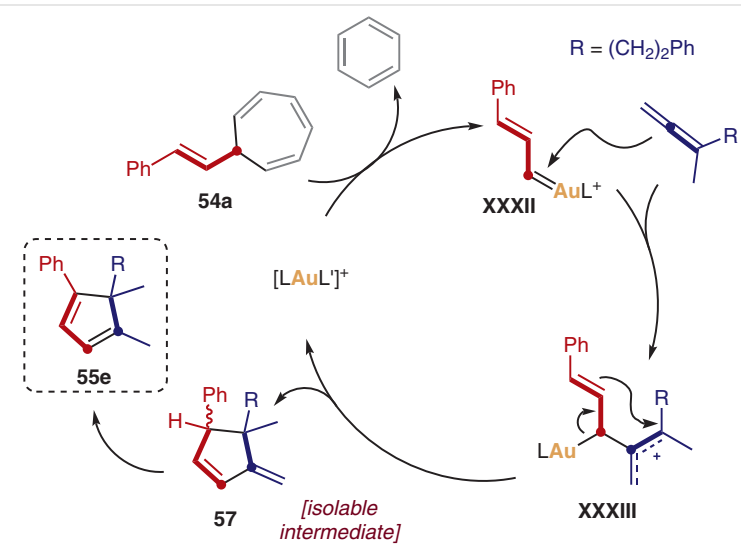

Scheme 27 Mechanism of the gold(I)-catalyzed formal (3+2) cycloaddition

\subsection{3 (4+3) Cycloadditions of Rh(II) Carbenes}

More recently, we found that alkenyl carbene precursors 58 reacted smoothly with 1,3-dienes under rhodium(II) catalysis to afford 1,4-cycloheptadienes as the products of formal $(4+3)$ cycloaddition..$^{35}$ The discovery of this reaction was made possible by the development of 7-alkenyl-1,3,5-trimethyl-1,3,5-cycloheptatrienes $\mathbf{5 8}$ as more reactive carbene precursors, which can undergo decarbenations or retro-Buchner reactions under mild conditions in the presence of either gold(I) or rhodium(II) catalysis. ${ }^{48}$ In this manner, we were able to prepare a very wide variety of mono- and bicyclic 1,4-cycloheptadienes $\mathbf{5 9}$ in good to excellent yields, and as single diastereoisomers (Scheme 28).

This strategy was employed for the straightforward total synthesis of the pheromone dictyopterene $C^{\prime}(\mathbf{5 9 i})$. The reaction of vinyl carbene precursor 58a with 1,3-butadiene

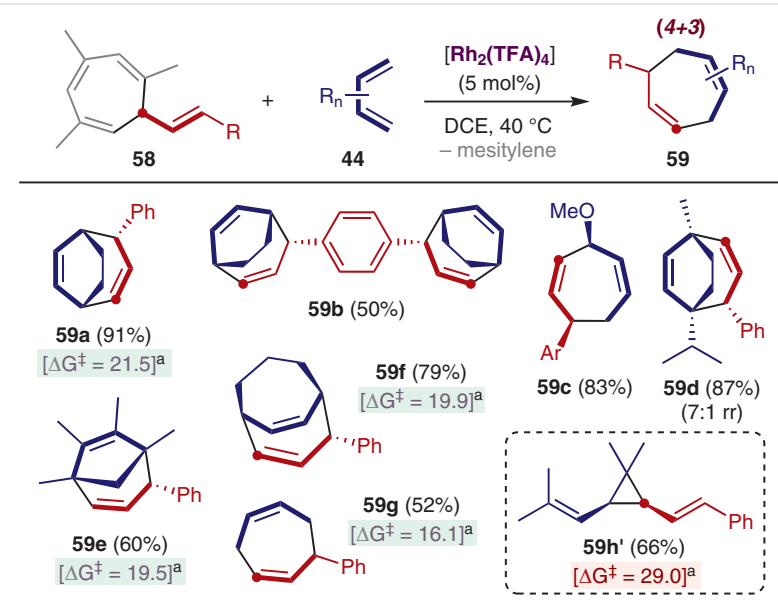

Scheme $28(4+3)$ Cycloaddition of alkenyl rhodium(II) carbenes and 1,3-dienes. $\mathrm{rr}=$ regioisomeric ratio. ${ }^{\text {a }}$ Energy barrier $(\mathrm{kcal} / \mathrm{mol})$ for the free Cope rearrangement of the corresponding divinylcyclopropanes (calculated by DFT).

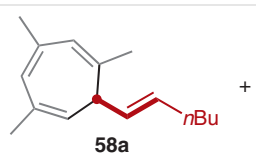

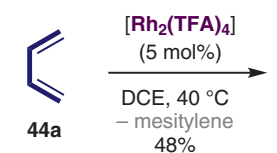<smiles>CCCCC1C=CCC=CC1</smiles>

Scheme 29 Total synthesis of dictyopterene $C^{\prime}$ by $(4+3)$ cycloaddition

(44a) in the presence of $\left[\mathrm{Rh}_{2}(\mathrm{TFA})_{4}\right]$ as the catalyst at $40{ }^{\circ} \mathrm{C}$ afforded directly the natural product (Scheme 29). ${ }^{35}$

The mechanism of this transformation takes place analogously to that described in Scheme 20 for the cascade cycloaddition of gold carbenes III with 1,3-dienes. DFT calculations revealed two different possible fates for adduct XXXIV, formed upon reaction of styryl rhodium(II) carbene with 1,3-cyclohexadiene (Scheme 30). First, this intermediate can close up directly to form the product of formal (4+3) cycloaddition XXXVI through $\mathbf{T S}_{\text {XxxIv-XxxyI }}(\Delta \mathrm{G}=2.4 \mathrm{kcal} / \mathrm{mol})$. Alternatively, XXXIV can close to give a three-membered ring through the slightly-lower-in-energy $\mathbf{T} \mathbf{S}_{\mathbf{x x x I V}-\mathbf{x x x v}}$, giving rise to 1,2-divinylcyclopropane 59a', which can then evolve through Cope rearrangement. This rearrangement was calculated to have similar barriers either in the presence or in the absence of the rhodium(II) catalyst. Following the overall process by ${ }^{1} \mathrm{H}$ NMR allowed the observation of a significant accumulation of divinylcyclopropane intermediate 59a', confirming the existence of the cyclopropanation/Cope rearrangement pathway in which the latter process can be considered the rate-limiting step. Furthermore, we observed that for some 1,3-dienes the product of vinylcyclopropanation (such as $\mathbf{5 9 h}^{\prime}$ ) was the only product obtained under the optimized reaction conditions. Thus, we developed a simple theoretical model using DFT that could be used to predict if certain reaction partners will afford 
the product of $(4+3)$ cycloaddition (Scheme 28 , barriers $<25$ $\mathrm{kcal} / \mathrm{mol}$ for the free Cope rearrangement) or the product of vinylcyclopropanation (Scheme 28, barriers $>25 \mathrm{kcal} / \mathrm{mol}$ for the free Cope rearrangement). To further support this mechanism, some of the obtained divinylcyclopropanes were transformed into the corresponding 1,4-cycloheptadienes by heating them above $140{ }^{\circ} \mathrm{C}$, either in the presence or in the absence of the rhodium(II) catalyst..$^{35}$

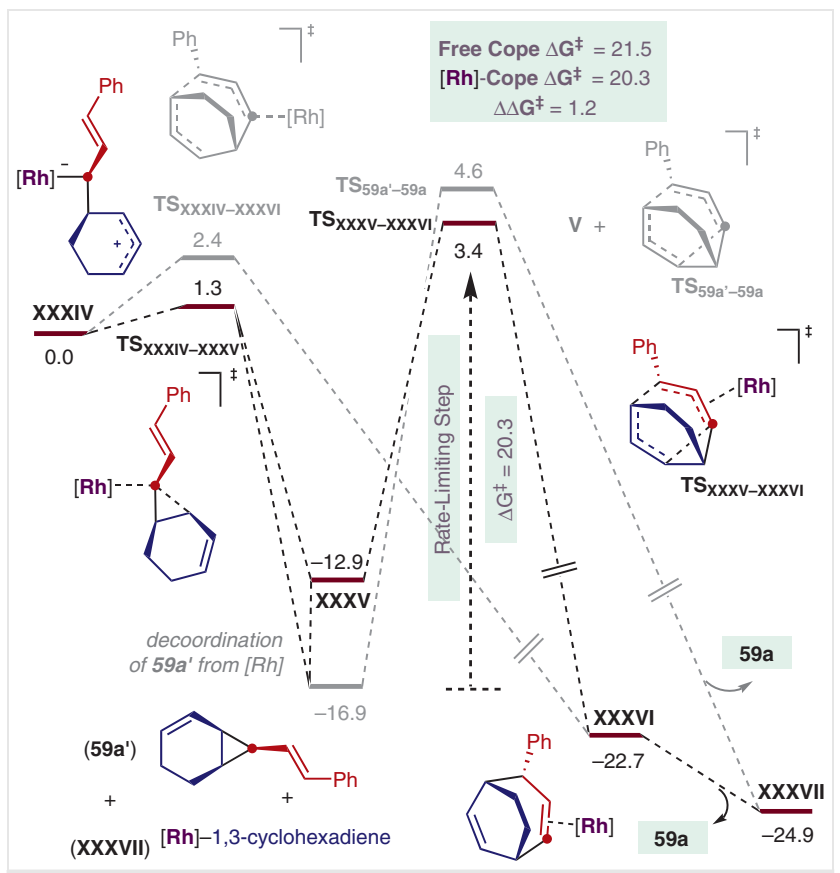

Scheme 30 DFT calculations of the (4+3) cycloaddition of styryl Rh(II) carbenes with 1,3-dienes. Values for free energies in $\mathrm{kcal} / \mathrm{mol}$. [Rh] = $\left[\mathrm{Rh}_{2}(\mathrm{TFA})_{4}\right]$.

\section{Concluding Remarks}

The field of homogeneous gold(I) catalysis started to blossom twenty years ago, but its true potential as a tool to construct highly complex structures in a single reaction step has truly been unveiled over the last decade. As we have aimed to illustrate in this account, many methodologies have emerged based on the metal-catalyzed selective activation of alkynes and other substrates, such as cycloheptatrienes, to generate non-acceptor carbene intermediates in situ. These highly versatile intermediates engage in a variety of downhill cascade or cycloaddition processes, rapidly assembling molecular complexity. These cyclization strategies have also been applied in the synthesis of natural products. Besides all the possible opportunities for reaction discovery that this type of tandem process has to offer, there is still progress to be made in order to further advance the field conceptually. For instance, the development of en- antioselective versions of many of these methodologies has not met with success thus far. Furthermore, the extension of this type of process to the use of more readily available and cheaper metal catalysts would be highly desirable.

\section{Conflict of Interest}

The authors declare no conflict of interest.

\section{Funding Information}

We thank the Ministerio de Ciencia e Innovación (PID2019104815GB-I00) (FPI predoctoral fellowship to M.M. and FPU predoctoral fellowship to H.A.-R.), Severo Ochoa Research Excellence Accreditation 2020-2023 (CEX2019-000925-S), the European Research Council (Advanced Grant No. 835080), the Agència de Gestió d'Ajuts Universitaris i de Recerca (AGAUR) (2017 SGR 1257), and the Centres de Recerca de Catalunya (CERCA) Program/Generalitat de Catalunya for financial support.

\section{Acknowledgment}

We would like to thank all the Echavarren group members that have contributed to the discovery and development of the reactions covered herein.

\section{References}

(1) (a) Hutchings, G. J. J. Catal. 1985, 96, 292. (b) Haruta, M.; Kobayashi, T.; Sano, H.; Yamada, N. Chem. Lett. 1987, 16, 405. (c) Hutchings, G. J. ACS Cent. Sci. 2018, 4, 1095.

(2) Teles, J. H.; Brode, S.; Chabanas, M. Angew. Chem. Int. Ed. 1998, $37,1415$.

(3) Hashmi, A. S. K.; Frost, T. M.; Bats, J. W. J. Am. Chem. Soc. 2000, 122,11553

(4) (a) Nieto-Oberhuber, C.; Muñoz, M. P.; Buñuel, E.; Nevado, C.; Cárdenas, D. J.; Echavarren, A. M. Angew. Chem. Int. Ed. 2004, 43, 2402. (b) Luzung, M. R.; Markham, J. P.; Toste, F. D. J. Am. Chem. Soc. 2004, 126, 10858. (c) Mamane, V.; Gress, T.; Krause, H.; Fürstner, A. J. Am. Chem. Soc. 2004, 126, 8654.

(5) (a) Nieto-Oberhuber, C.; Muñoz, M. P.; López, S.; JiménezNúñez, E.; Nevado, C.; Herrero-Gómez, E.; Raducan, M.; Echavarren, A. M. Chem. Eur. J. 2006, 12, 1677. (b) Nieto-Oberhuber, C.; López, S.; Muñoz, M. P.; Jiménez-Núñez, E.; Buñuel, E.; Cárdenas, D. J.; Echavarren, A. M. Chem. Eur. J. 2006, 12, 1694. (c) Nieto-Oberhuber, C.; López, S.; Jiménez-Núñez, E.; Echavarren, A. M. Chem. Eur. J. 2006, 12, 5916.

(6) (a) Jiménez-Núñez, E.; Echavarren, A. M. Chem. Rev. 2008, 108, 3326. (b) Fürstner, A. Chem. Soc. Rev. 2009, 38, 3208. (c) Obradors, C.; Echavarren, A. M. Acc. Chem. Res. 2014, 47, 902. (d) Fensterbank, L.; Malacria, M. Acc. Chem. Res. 2014, 47, 953. (e) Dorel, R.; Echavarren, A. M. Chem. Rev. 2015, 115, 9028. (f) Pflästerer, D.; Hashmi, A. S. K. Chem. Soc. Rev. 2016, 45, 1331. (g) Echavarren, A. M.; Muratore, M.; López-Carrillo, V.; Escribano-Cuesta, A.; Huguet, N.; Obradors, C. Org. React. 2017, 92, 1. (h) Mato, M.; Franchino, A.; García-Morales, C.; Echavarren, A. M. Chem. Rev. 2021, 121, 8613.

(7) Jiménez-Nuñez, E.; Echavarren, A. M. Chem. Commun. 2007, 333. 
(8) (a) Kennedy-Smith, J. J.; Staben, S. T.; Toste, F. D. J. Am. Chem. Soc. 2004, 126, 4526. (b) Hashmi, A. S. K.; Weyrauch, J. P.; Frey, W.; Bats, N. W. Org. Lett. 2004, 6, 4391. (c) García-Mota, M.; Cabello, N.; Maseras, F.; Echavarren, A. M.; Pérez-Ramírez, J.; López, N. ChemPhysChem 2008, 9, 1624.

(9) (a) Day, D. P.; Chan, P. W. H. Adv. Synth. Catal. 2016, 358, 1368. (b) Mayans, J. G.; Armengol-Relats, H.; Calleja, P.; Echavarren, A. M. Isr. J. Chem. 2018, 58, 639 .

(10) (a) López-Carrillo, V.; Echavarren, A. M. J. Am. Chem. Soc. 2010, 132, 9292. (b) Homs, A.; Obradors, C.; Leboeuf, D.; Echavarren, A. M. Adv. Synth. Catal. 2014, 356, 221. (c) de Orbe, M. E.; Amenós, L.; Kirillova, M. S.; Wang, Y.; López-Carrillo, V.; Maseras, F.; Echavarren, A. M. J. Am. Chem. Soc. 2017, 139, 10302. (d) García-Morales, C.; Ranieri, B.; Escofet, I.; LópezSuarez, L.; Obradors, C.; Konovalov, A. I.; Echavarren, A. M.J. Am. Chem. Soc. 2017, 139, 13628 .

(11) Examples on gold(I)-catalyzed 1,2-acyl migration of propargylic carboxylates: (a) Johansson, M. J.; Gorin, D. J.; Staben, S. T.; Toste, F. D. J. Am. Chem. Soc. 2005, 127, 18002. (b) Marion, N.; Nolan, S. P. Angew. Chem. Int. Ed. 2007, 46, 2750. (c) Amijs, C. H. M.; López-Carrillo, V.; Echavarren, A. M. Org. Lett. 2007, 9, 4021. (d) Witham, C. A.; Mauleón, P.; Shapiro, N. D.; Sherry, B. D.; Toste, F. D. J. Am. Chem. Soc. 2007, 129, 5838. (e) Correa, A.; Marion, N.; Fensterbank, L.; Malacria, M.; Nolan, S. P.; Cavallo, L. Angew. Chem. Int. Ed. 2008, 47, 718. (f) Sun, Y.-W.; Tang, X.-Y.; Shi, M. Chem. Commun. 2015, 51, 13937. (g) Li, Y.; Zhu, C.-Z.; Zhang, J. Eur. J. Org. Chem. 2017, 6609. (h) Zhao, J.; Yang, S.; Xie, X.; Li, X.; Liu, Y.J. Org. Chem. 2018, 83, 1287.

(12) Examples on gold(I)-catalyzed activation of cyclopropenes: (a) Hadfield, M. S.; Lee, A.-L. Chem. Commun. 2011, 47, 1333. (b) Young, P. C.; Hadfield, M. S.; Arrowsmith, L.; Macleod, K. M.; Mudd, R. J.; Jordan-Hore, J. A.; Lee, A.-L. Org. Lett. 2012, 14, 898. (c) Drew, M. A.; Arndt, S.; Richardson, C.; Rudolph, M.; Hashmi, A. S. K.; Hyland, C. J. T. Chem. Commun. 2019, 55, 13971. (d) González, J.; de la Fuente, A.; González, M. J.; Díez de Tejada, L.; López, L. A.; Vicente, R. Beilstein J. Org. Chem. 2019, 15, 285.

(13) Jiménez-Núñez, E.; Raducan, M.; Lauterbach, T.; Molawi, K.; Solorio, C. R.; Echavarren, A. M. Angew. Chem. Int. Ed. 2009, 48, 6152.

(14) Dorel, R.; McGonigal, P. R.; Echavarren, A. M. Angew. Chem. Int. Ed. 2016, 128, 11286.

(15) Carreras, J.; Livendahl, M.; McGonigal, P. R.; Echavarren, A. M. Angew. Chem. Int. Ed. 2014, 53, 4896.

(16) Jiménez-Núñez, E.; Claverie, C. K.; Nieto-Oberhuber, C.; Echavarren, A. M. Angew. Chem. Int. Ed. 2006, 45, 5452.

(17) Calleja, P.; Muratore, M. E.; Jiménez, T.; Echavarren, A. M. Synthesis 2016, 48, 3183.

(18) Muratore, M. E.; Konovalov, A. I.; Armengol-Relats, H.; Echavarren, A. M. Chem. Eur. J. 2018, 24, 15613.

(19) Escribano-Cuesta, A.; López-Carrillo, V.; Janssen, D.; Echavarren, A. M. Chem. Eur. J. 2009, 15, 5646.

(20) Huple, D. B.; Liu, R. S. Chem. Commun. 2012, 48, 10975.

(21) Jiménez-Núñez, E.; Molawi, K.; Echavarren, A. M. Chem. Commun. 2009, 7327.

(22) (a) Molawi, K.; Delpont, N.; Echavarren, A. M. Angew. Chem. Int. Ed. 2010, 49, 3517. (b) López-Suárez, L.; Riesgo, L.; Bravo, F.; Ransom, T. T.; Beutler, J. A.; Echavarren, A. M. Chem. Med Chem. 2016, 11, 1003. (c) Wu, Z.; Suppo, J. S.; Tumova, S.; Strope, J.; Bravo, F.; Moy, M.; Weinstein, E. S.; Peer, C. J.; Figg, W. D.; Chain, W. J.; Echavarren, A. M.; Beech, D. J.; Beutler, J. A. ACS Med. Chem. Lett. 2020, 11, 1711.
(23) Zhou, Q.; Chen, X.; Ma, D. Angew. Chem. Int. Ed. 2010, 49, 3513.

(24) Liu, J.-Q.; Yang, Y.-F.; Wang, C.-F.; Li, Y.; Qiu, M.-H. Tetrahedron 2012, 68, 972.

(25) Escofet, I.; Armengol-Relats, H.; Bruss, H.; Besora, M.; Echavarren, A. M. Chem. Eur. J. 2020, 26, 15738.

(26) Cronan, J. M. Jr.; Daviau, T. R.; Pannell, L. K.; Cardellina, J. H. II. J. Org. Chem. 1995, 60, 6864.

(27) Brochini, C. B.; Roque, N. F. J. Braz. Chem. Soc. 2000, 11, 361.

(28) Yang, Z.; Chen, H.; Li, Y. Helv. Chim. Acta 2003, 86, 3305.

(29) Gaydou, M.; Miller, R. E.; Delpont, N.; Ceccon, J.; Echavarren, A. M. Angew. Chem. Int. Ed. 2013, 52, 6396.

(30) Mou, S.-B.; Xiao, W.; Wang, H.-Q.; Chen, K.-Y.; Xiang, Z. Org. Lett. 2021, 23, 400 .

(31) Lebœuf, D.; Gaydou, M.; Wang, Y.; Echavarren, A. M. Org. Chem. Front. 2014, 1, 759.

(32) Calleja, P.; Pablo, Ó.; Ranieri, B.; Gaydou, M.; Pitaval, A.; Moreno, M.; Raducan, M.; Echavarren, A. M. Chem. Eur.J. 2016, 22, 13613.

(33) Shiroodi, R. K.; Gevorgyan, V. Chem. Soc. Rev. 2013, 42, 4991.

(34) Benitez, D.; Shapiro, N. D.; Tkatchouk, E.; Wang, Y.; Goddard, W. A. III.; Toste, F. D. Nature Chem. 2009, 1, 482.

(35) Armengol-Relats, H.; Mato, M.; Echavarren, A. M. Angew. Chem. Int. Ed. 2021, 60, 1916.

(36) Xu, X.; Doyle, M. P. Acc. Chem. Res. 2014, 47, 1396.

(37) Zhu, D.; Chen, L.; Fan, H.; Yao, Q.; Zhu, S. Chem. Soc. Rev. 2015, $49,908$.

(38) (a) Zhang, L. Acc. Chem. Res. 2014, 47, 877. (b) Harris, R. J.; Widenhoefer, R. A. Chem. Soc. Rev. 2016, 45, 4533. (c) Jia, M.; Ma, S. Angew. Chem. Int. Ed. 2016, 55, 9134.

(39) Wei, F.; Song, C.; Ma, Y.; Zhou, L.; Tung, C.-H.; Xu, Z. Sci. Bull. 2015, 60, 1479.

(40) Fulton, J. R.; Aggarwal, V. K.; de Vicente, J. Eur. J. Org. Chem. 2005, 1479.

(41) Miege, F.; Meyer, C.; Cossy, J. Beilstein J. Org. Chem. 2011, 7, 717.

(42) Mato, M.; García-Morales, C.; Echavarren, A. M. ChemCatChem 2019, 11, 53.

(43) Solorio-Alvarado, C. R.; Echavarren, A. M. J. Am. Chem. Soc. 2010, $132,11881$.

(44) (a) Solorio-Alvarado, C. R.; Wang, Y.; Echavarren, A. M. J. Am. Chem. Soc. 2011, 133, 11952. (b) Mato, M.; Martín-Torres, I.; Herlé, B.; Echavarren, A. M. Org. Biomol. Chem. 2019, 17, 4216.

(45) Herlé, B.; Holstein, P. M.; Echavarren, A. M. ACS Catal. 2017, 7, 3668.

(46) Wang, Y.; McGonigal, P. R.; Herlé, B.; Besora, M.; Echavarren, A. M. J. Am. Chem. Soc. 2014, 136, 801.

(47) Mato, M.; Herlé, B.; Echavarren, A. M. Org. Lett. 2018, 20, 4341.

(48) Mato, M.; Echavarren, A. M. Angew. Chem. Int. Ed. 2019, 58, 2088.

(49) Mato, M.; García-Morales, C.; Echavarren, A. M. ACS Catal. 2020, $10,3564$.

(50) Wang, Y.; Muratore, M. E.; Rong, Z.; Echavarren, A. M. Angew. Chem. Int. Ed. 2014, 53, 14022.

(51) de Orbe, M. E.; Echavarren, A. M. Eur. J. Org. Chem. 2018, 2740.

(52) Yin, X.; Mato, M.; Echavarren, A. M. Angew. Chem. Int. Ed. 2017, $56,14591$.

(53) For a recent enantioselective total synthesis and structural revision of dysiherbol A, see: Baars, J.; Grimm, I.; Blunk, D.; Neudörfl, J.-M.; Schmalz, H.-G. Angew. Chem. Int. Ed. 2021, 60, 14915. 